\title{
ESTUDO DA VARIABILIDADE PLUVIOMÉTRICA NO EXTREMO NORTE DO ESTADO DE MATO GROSSO ENTRE OS ANOS DE 1990 A 1996
}

Romário Rosa de Sousa ${ }^{1}$, Deocleciano Bittencourt Rosa ${ }^{2}$, Lucelma Aparecida Nascimento ${ }^{3}$, Paulo Roberto Menezes Lima ${ }^{4}$

(1 - Mestrando do Programa de Pós-Graduação em Geografia/Instituto de Ciências Humanas e Sociais/UFMT, romarioufg@yahoo.com.br; 2 - Prof. do Departamento de Geografia/ICHS/UFMT, dbrosa@terra.com.br; 3 - Geógrafa, lucelmamt@yahoo.com.br; 4 Faculdades Terra-Brasília. SQS 108, Bloco B, Apto 401. 70.346-020 - Brasília, Distrito Federal. paulomenezes@,bb.com.br)

\section{Resumo}

A precipitação é entendida como toda água proveniente do meio atmosférico que atinge a superfície terrestre. Ela ocorre sob as formas pluviais (chuva), de granizo e de neve. O objetivo principal deste trabalho foi analisar a variabilidade pluviométrica no extremo Norte do Estado de Mato de Grosso ocorrido no período de 1990 a 1996, identificando os municípios que tiveram mais e menos acúmulos pluviométricos nesta região do estado, com posterior geração de mapas de isoietas através de técnicas de interpolação. Observando-se os mapas de isoietas de 1990 a 1996, identificou-se que, preferencialmente, as chuvas ocorreram em maior quantidade nas porções Norte e Oeste da área de estudos. Contudo nas porções Sul e Leste, foram registrados os menores índices pluviométricos, com exceção apenas para os anos de 1992 e 1993, onde se registrou as maiores somas. Evidenciou-se também que a porção Sul, sempre se registrou as menores somatórias pluviométricas ao longo da série estudada. Notou-se que os regimes anuais pluviométricos se comportaram de forma bem variável ao longo do período estudado.

Palavras-Chave: Precipitação, variabilidade pluviométrica, Chuva.

\section{Abstract \\ PLUVIOMETRIC VARIABILITY BETWEEN THE YEARS OF 1990 AND 1996 ON THE NORTH OF MATO GROSSO STATE - BRAZIL}

The precipitation is understood as all water proceeding from the atmospheric way that reaches the terrestrial surface. It occurs under the forms pluvial (rain), of hail and snow. The main objective of this work was to analyze the pluviometrical variability in the North extremity of 


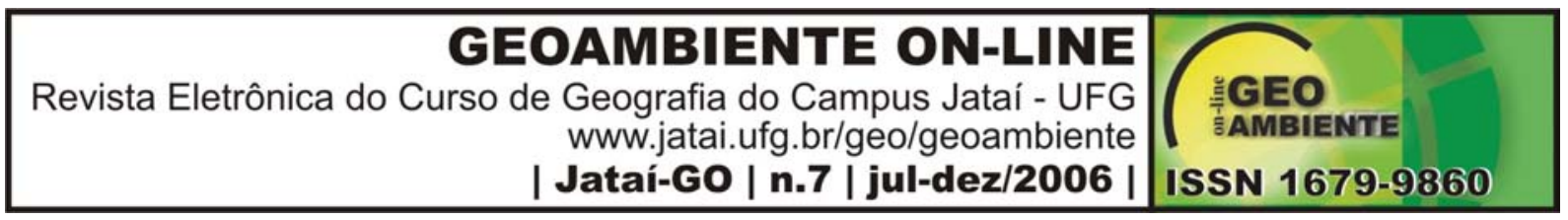

the Mato Grosso state of weeds of thick occurrence in the period of 1990 the 1996, identifying the cities that had more and little pluviometrical accumulations in this region of the state, with posterior generation of maps of isoyetas through interpolation techniques. Observing the maps of isoyetas of 1990 the 1996, were identified that preferential, rains had occurred in bigger amount in the portions North and West of the studies area. However in the South and East portions, they had been registered the lesser pluviometrical indices, with exception only for the years of 1992 and 1993, where if it registered the biggest additions. It was also proven that the South portion, always registered the minors pluviometrical additions to the long one of the studied series. One noticed that regimes annual pluviométrical if had held of well changeable form to the long one of the studied period.

Key words: Precipitation, pluviometrical variability, rain.

\section{1 - Introdução}

A água na Terra é a essência da vida, e representa o constituinte inorgânico mais abundante na matéria viva. O homem possui $63 \%$ de sua massa constituída de água, sendo que alguns animais aquáticos são constituídos de cerca de $98 \%$ desse composto. Desta forma a biomassa contida na superfície terrestre é sensivelmente proporcional ao volume das precipitações pluviométricas (Ramade, 1974).

Procurar entender a dinâmica das chuvas segundo Vila (1975) é algo tão antigo, quanto à própria civilização. Há registros de trabalhos feitos pelos chineses, antes de Cristo e posteriormente ao longo do caminhar da humanidade, e cada vez mais houve o interesse de conhecer melhores os fatores e elementos climáticos, e a exemplo disso existem relatos, que guerreiros no período medieval, eram incumbidos de ficarem observando as aproximações das nuvens nas imediações dos castelos ao longo dos cultivos, e tendo os mesmos a incumbência de avisarem com antecedência da probabilidade de ocorrência de chuva no reino.

O homem através das práticas de desmatamentos, urbanização, atividades agropecuárias e outros fatores, garante a sua permanência de uso e ocupação do solo, tornando-se cada vez mais dependente das condições atmosféricas, uma vez que as condições de tempo não são totalmente previsíveis, onde a agricultura, por exemplo, é uma atividade de risco em virtude de secas prolongadas, ocorrências veranicos (períodos secos dentro de uma estação chuvosa) e chuvas excessivas.

Numa época de grandes transformações ambientais, onde as alternâncias de períodos chuvosos e secos assumem proporções de calamidade, em função da intensidade da ocupação 


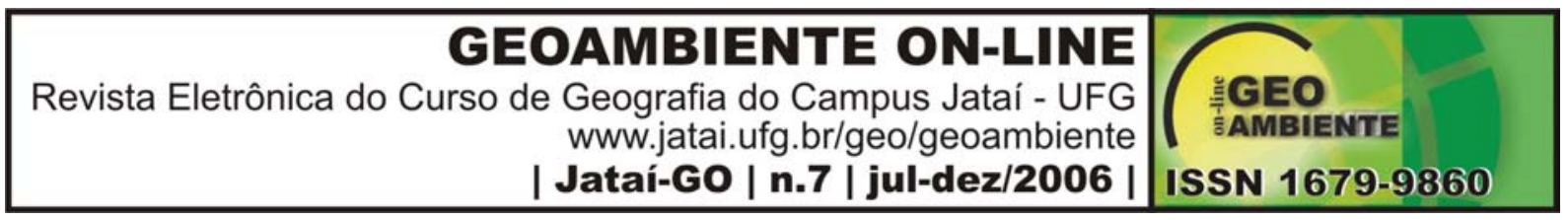

humana, quer nas atividades agrárias, ou nas aglomerações urbanas, torna-se inegável o controle das intervenções de natureza humana no meio ambiente Sant'Anna Neto, (2000).

Tais acontecimentos, segundo Monteiro et al. (1971), têm surgido não somente em situações regionais ou locais, mas também em nível nacional. Assim as irregularidades climáticas têm se revelado em diferentes regiões com repercussões bem significativas nas atividades humanas, sobretudo na rede urbana e na zona rural afetando assim as atividades agrícolas e pecuárias.

As quantidades relativas de precipitações, o volume, seus regimes sazonais ou diários, a distribuição temporal e as intensidades de chuvas individuais (volume/duração), são algumas das características que afetam direta ou indiretamente a população, a economia e o meio ambiente. Dessa forma as intervenções de natureza humana podem alterar drasticamente o ciclo chuvoso e seco de uma região, podendo até aumentar ou diminuir em proporções maiores (Monteiro, 2000).

Variações pluviométricas totais mensais e anuais das chuvas acontecem e refletem o comportamento da circulação atmosférica regional ao longo do ano (fator genético), interrelacionadas aos fatores de natureza geográfica (locais ou regionais). Estas variações a partir de dados de Rossato et al. (2003), são intrinsecamente, reflexos da própria dinamicidade da atmosfera, e diante de toda a dinâmica da variabilidade pluviométrica nota-se que as intervenções de natureza humana, de forma desordenada podem ocasionar danos irreversíveis à natureza.

A precipitação é sem duvida um dos fenômenos que mais afetam todas as atividades humanas. Pode ser considerada como um dos fatores mais influentes nas condições ambientais, sendo que a quantidade e a intensidade da mesma pode determinar o sucesso ou o fracasso numa atividade. A importância de se estudar essa variável meteorológica é mostrar que se podem prevenir vários transtornos que a chuva possa causar.

Diante dessas premissas, o objetivo principal deste trabalho foi analisar a variabilidade pluviométrica ocorrida de 1990 a 1996, identificando os municípios que tiveram mais e menos acúmulos pluviométricos no extremo Norte do Estado de Mato de Grosso, e com posterior geração de mapas de isoietas, através de técnicas de interpolação.

\section{2 - Localização e Acesso}

O Estado de Mato Grosso está localizado entre as coordenadas geográficas de latitudes $7^{\circ}$ a $18^{\circ} \mathrm{Sul}$ e longitudes $50^{\circ}$ a $62^{\circ}$ Oeste de Greenwich. As altitudes variam de 100 a 1200 metros, no centro do Continente Sul Americano. 
A área de estudo dentro do estado está compreendida entre as coordenadas geográficas de latitudes $7^{\circ} 48^{\prime}$ a $12^{\circ}$ Sul e longitudes $50^{\circ}$ e $61^{\circ}$ Oeste de Greenwich, situando-se aproximadamente $520 \mathrm{~km}$ da cidade de Cuiabá, a capital de Mato Grosso (Figura 1).

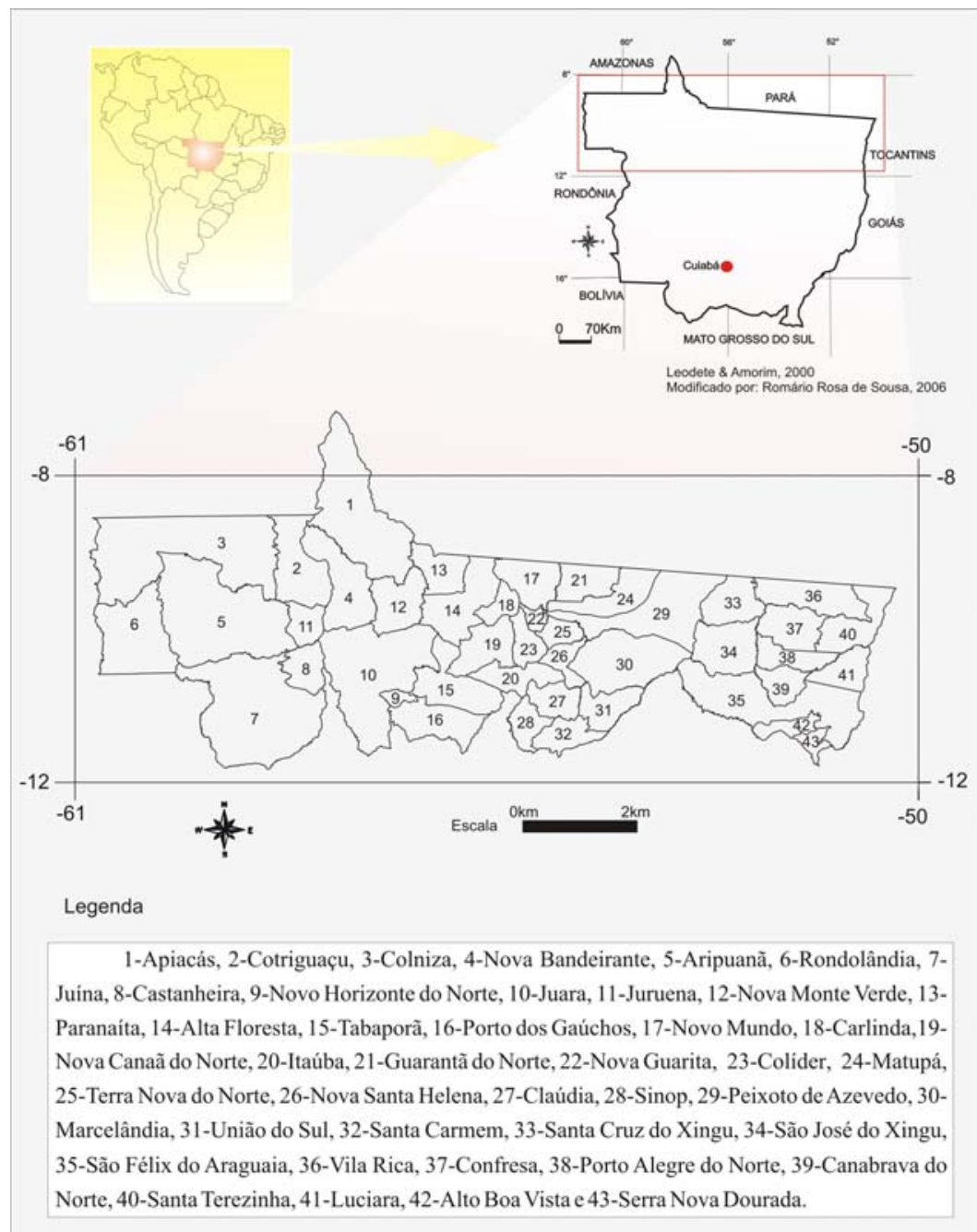

Figura 1 - Mapa de localização da área de estudo no Estado de Mato Grosso.

O acesso área de estudo é possibilitado através das Rodovias Federais (BR): 070, 158, 163 e 364, e Rodovias Estaduais (MT): 206, 108, 170, 174 e 130.

Um total de 43 municípios compõem esta área, ou sejam: Alta Floresta, Alto Boa Vista Apiacás, Aripuanã, Canabrava do Norte, Carlinda, Castanheira, Claúdia, Colíder, Colniza, Confresa, Cotriguaçu, Guarantã do Norte, Itaúba, Juara, Juína, Juruena, Luciara, Matupá, Marcelândia, Nova Bandeirante, Nova Canaã do Norte, Nova Guarita, Nova Monte Verde, Nova Santa Helena, Novo Horizonte do Norte, Novo Mundo, Paranaíta, Peixoto de Azevedo, Porto Alegre do Norte, Porto dos Gaúchos, Rondolândia, Santa Carmem, Santa Cruz do Xingu, Santa Terezinha, São Félix do Araguaia, São José do Xingu, Serra Nova Dourada, Sinop, Tabaporã, Terra Nova do Norte, União do Sul e Vila Rica. 


\section{2 - Metodologia}

Os trabalhos metodológicos seguiram a proposta de Matheron (1965), citado por Assad et al. (1994), onde foram realizados através de procedimentos teóricos e práticos, baseando-se nos dados cedidos pela Agência Nacional de Águas (ANA), provindos de postos coletores fixados na área de estudo. Os dados foram organizados primeiramente em Sob a forma de arquivos ASCII, de onde foram extraídos os totais anuais, e transportados para planilha eletrônica, para a realização de recobrimento de falha, pelo método de ponderação regional, usando a seguinte equação: $y=\frac{1}{3}\left[\frac{x 1}{X m 1}+\frac{x 2}{X m 2}+\frac{x 3}{X m 3}\right] \cdot y m ;$ onde: $\mathrm{y}_{c}$ é a precipitação do Posto $\mathrm{Y}$ a ser estimada x1, x2 e x3= as precipitações correspondentes ao ano que se desejou preencher, observada em três postos de coletas vizinhos $y m=$ a precipitação média do posto $\mathrm{Y}$; $\mathrm{xm} 1, \mathrm{xm} 2, \mathrm{xm} 3=$ as precipitações médias nos três postos de coleta circunvizinhos.

Após o preenchimento de falhas, quando necessário realizou-s a regressão linear múltipla para se verificar e ter a consistência dos dados utilizando a equação: $\mathrm{y}_{\mathrm{c}}=X l i+a 1 \times 2 \mathrm{i}$ $+\cdots+$ an $-1 \mathrm{Xn} 1+\mathrm{na} ;$ onde $\mathrm{n}=\mathrm{o}$ número de postos considerados, ao, a1, $\cdots$, na $=$ os coeficientes a serem estimados e xli, x2i, $\cdots$, xni $=$ as observações correspondentes registradas nos postos vizinhos.

Posteriormente os valores foram organizados de acordo as coordenadas geográficas, ou seja, onde a Longitude: X-representam a distância leste de uma marca de nível medida dentro [ $\mathrm{m}$ ]; Latitude Y-representam o norte da distância de uma marca de nível medida também dentro [ $\mathrm{m}$ ]; Z-representa a intensidade do rainfall medida dentro [ $\mathrm{cm} / \mathrm{hr}$ ], que esta corresponde aos valores os dados hidroclimáticos a serem espacializados, tendo como resultado final à geração de mapas de isoietas no programa de Surfer versão 8, pertencente a Golden Software. No momento da interpolação foi definido um intervalo médio $150 \mathrm{~mm}$, entre um valor e outro de quantidade em milímetros de chuva, sendo que isso possibilitou uma melhor padronização e interpretação dos mapas.

A área de estudos está representada por três compartimentações geomorfológicas, onde evidenciamos a Depressão Interplanáltica da Amazônia Meridional, O Planalto Residual do Norte do Mato Grosso e o Planalto dos Parecís (Melo \& Franco, 1980).

A Depressão Interplanáltica da Amazônia Meridional se descortina através de um corredor constituído por rochas pertencentes às unidades litodêmicas Complexo Xingu (Silva et al. 1972) e Granitóide Paranaíta (Bittencourt Rosa et al. 1997), apresentando-se em longo processo de exposição e arrasamento, esculpindo relevos via de regra planos com elevações 
esparsas, onde as cotas oscilam entre 150 a 180 metros.

O Planalto Residual do Norte do Mato Grosso corresponde à unidade geomorfológica representada pelas Serras do Cachimbo e Caiabís. As altitudes variam entre 400 a 520 metros, e se configuram em interflúvios que formam os modelados dos relevos residuais embutidos na Depressão Interplanáltica da Amazônia Meridional.

O Planalto dos Parecis primeiramente estudado por Derby (1895) está compartimentado pelo Planalto Dissecado dos Parecís e a Chapada dos Parecis, onde o primeiro é a unidade geomorfológica que abrange uma expressiva área de planaltos distribuída, através de terrenos paleozóicos e cenozóicos, constituindo a divisor de águas entre as Bacias Platina e Amazônica, cujo relevo se apresenta segundo Werle \& Alves da Silva (1996) dissecado com formas tabulares de grande amplitude, elevações residuais com cimos planos, bordejadas por escarpas que constituem patamares estruturais escalonados.

A Chapada dos Parecís abrange, uma expressiva área aplainada, com altitudes que atingem os 550 metros, recoberta por um depósito de Cobertura Detrito-Laterítica de idade Tércio-Quaternária.

Em face da retomada dos processos erosivos à Chapada dos Parecís vem sendo alvo de um recuo através da dissecação em anfiteatros erosivos que geralmente se unem constituindo vales amplos e profundos, bordejados por escarpas abruptas.

O Planalto dos Parecis é o grande divisor de águas entre a Bacia Amazônica ao Norte e a Bacia Platina ao Sul. Esta vasta área, posicionada entre a zona intertropical (Floresta amazônica), savanas tropicais (Cerrado) e a Depressão Continental do Chaco (Pantanal) ao Sul, sob o ponto de vista do quadro natural, garante-lhe características marcantes. Desta forma, o Estado de Mato Grosso encontra-se numa área de transição entre a atuação dos fluxos Tropical, Equatorial e Extratropical, os quais produzem tipos de tempos bem característicos desta região.

O Estado de Mato Grosso possui áreas significativas que abrangem três grandes ecossistemas naturais: O Pantanal, o Cerrado e a Floresta Amazônica. A área em estudo é constituída com a vegetação de Floresta Amazônica.

A cobertura vegetal de floresta ainda é presente principalmente nos setores ao Norte das Bacias Hidrográficas dos Rios Juruena e Teles Pires, destacando-se a Floresta Semidecidual Dossel Emergente, que corresponde segundo Amaral et al. (1982), citado por Bittencourt Rosa et al, (2002), a uma única formação vegetal que corresponde à floresta aluvial com dossel emergente, encontrada nas planícies e terraços aluviais, notadamente em 
terrenos terciários e quaternários recobertos por Neossolos Quartzarênicos Hidromórficos (EMBRAPA, 1999) às vezes inundáveis.

\section{3 - Resultados e Discussão}

Dados de Monteiro (1964, 1969) citado por Sette (2002), modificados, á partir de estudos de Serra \& Rattsbonna (1942) apresentam um esquema didático, para a interpretação e análise dos sistemas atmosféricos na América do Sul. Neste esquema os principais sistemas atmosféricos que atuam na região central do Brasil são: Massa Tropical Continental (MTc); Massa Equatorial Continental (MEc); Massa Tropical Atlântica (MTa); Massa Equatorial Atlântica (MEa); Massa Equatorial do Atlântico Norte (MEn); Massa Polar Atlântica (MPa); Frente Polar Atlântica (FPA) e Zona de Convergência Intertropical (ZCIT).

A atuação destes sistemas no extremo Norte e Nordeste do Estado de Mato Grosso está associada com a convergência dos alísios dentro do continente, ou pelo giro dos alísios de Sudeste, passando para Leste, Nordeste, Noroeste, em direção a baixa continental, neste caso, é denominada de Instabilidades de Norte Nordeste (INE).

O pioneiro em realizar uma caracterização da circulação de superfície para o antigo Estado do Mato Grosso (MT e MS) foi Serra (1948), que descreveu o ritmo sazonal dos movimentos da baixa atmosfera para as quatro estações do ano. Nimer (1979) com base nos trabalhos de Serra (1948) realizou posteriormente um estudo onde ressalta dois fatores geográficos, ou seja, o relevo e a latitude como responsáveis da diversificação térmica. Por outro lado coloca o mecanismo atmosférico determinante na "marcha estacional de precipitação pluviométrica”, que é máxima no verão e mínima no inverno adequando uma uniformidade regional.

De acordo com a classificação climática de Durand Dastès (1968), para as grandes linhas do clima, modificada por Estienne \& Godard (1970), as temperaturas localmente, podem variar, entre $24^{\circ}$ a $36^{\circ} \mathrm{C}$ durante a estação chuvosa, cuja pluviometria média regional foi de $1.700 \mathrm{~mm}$. A umidade relativa do ar é variável e durante a estação das chuvas pode atingir a faixa dos $80 \%$, enquanto que na estação seca ela é de aproximadamente de $50 \%$.

O sistema de circulação atmosférica na região Centro-Oeste é constituído por ventos que sopram à Oeste (IT) - Linha de Instabilidades Tropicais, Norte (CIT) - Convergência Inter-tropical e Sul (FP) - Anticiclone Polar e Frente Polar, e desta forma a pluviosidade em Mato Grosso se deve exclusivamente, ao regime de circulação atmosférica (Nimer, 1979).

A média anual da precipitação de um núcleo mais chuvoso ao Norte de Mato Grosso pode atingir valores superiores a $2.750 \mathrm{~mm}$. Tais índices diminuem nas direções Leste, Oeste e 


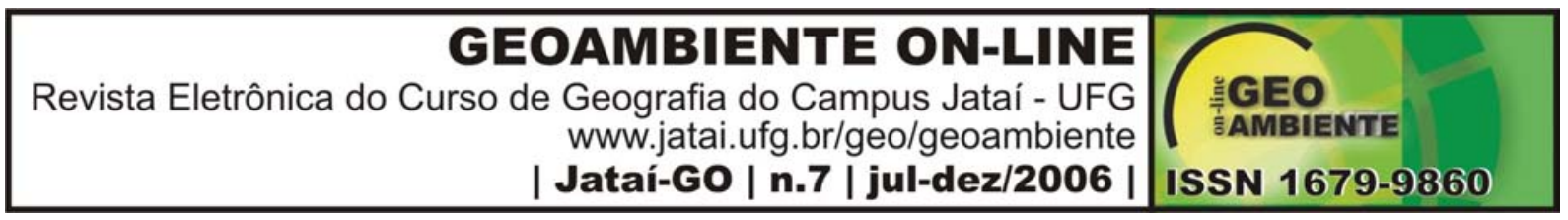

Sul do estado, resultando numa precipitação que se distribui de forma irregular durante todo o ano, onde o verão é o seu máximo e o inverno é o seu mínimo, sendo que $70 \%$ do total de chuvas acumuladas durante o ano se precipitam entre novembro a março, cujos meses mais chuvosos concentram-se no intervalo de janeiro a março. Durante esse trimestre a precipitação chega atingir de $45 \%$ até 55\% do total anual das chuvas (Nimer \& Brandão 1989).

Do ponto de vista agro-climatológico a região dos cerrados está sujeita a regime de secas dentro da estação chuvosa, a qual pode persistir de duas, três semanas e capaz chegar até um mês ou mais sem chuvas, cujo fenômeno é denominado de veranico. (Assad, et al. 1994). Casarim (1983) argumenta que o fenômeno veranico é causado por bloqueios de grande escala no escoamento atmosférico, sendo desse ponto de vista, o mecanismo do veranico pode estar associado aos deslocamentos da zona de convergência tropical e ao fenômeno "El Nino, diretamente relacionado com o aumento da temperatura do Oceano Pacífico".

Em contrapartida o inverno é extremamente seco, e é nessa época que as chuvas são raras com precipitações de quatro a cinco dias nos meses de junho, julho e agosto, concentra totais muito baixos, entre 20 e $80 \mathrm{~mm}$ de pluviosidade, fazendo com que a região fique na dependência quase exclusiva das chuvas frontais, que são proporcionadas pela passagem de frentes polares trazidas do sul pelo anticiclone polar(FK). Assim as ocorrências de chuvas no extremo Norte do Estado de Mato Grosso são conseqüências do sistema de circulação perturbada de W (IT), Tarifa, et al (2006). Dessa forma, as áreas de maior pluviosidade correspondem ao extremo norte e noroeste do Estado, nestas áreas os totais médios anuais variam entre 2.100 a $2.500 \mathrm{~mm}$.

O trimestre de setembro a novembro é caracterizado por temperaturas extremamente aquecidas no equinócio de primavera (Outubro-Novembro), com pouca ocorrência de precipitações e o aumento gradativo do regime pluviométrico só vai acontecer com o final da primavera, coincidindo com o início do verão no mês de dezembro. (Assad, et al. 1994). O Vale do Araguaia é o que apresenta os menores totais pluviométricos com (10 a 20mm).

Diante da série estudada 6 (seis) anos de dados analisados, notou-se que a pluviométrica comportou-se de forma bem variável, onde apenas no ano de 1990 (Figura 2) a soma da chuva acumulada foi igual a $2.750 \mathrm{~mm}$, sendo que nos demais anos a soma total ficou sempre abaixo da média estipulada por Nimer \& Brandão (1989). 

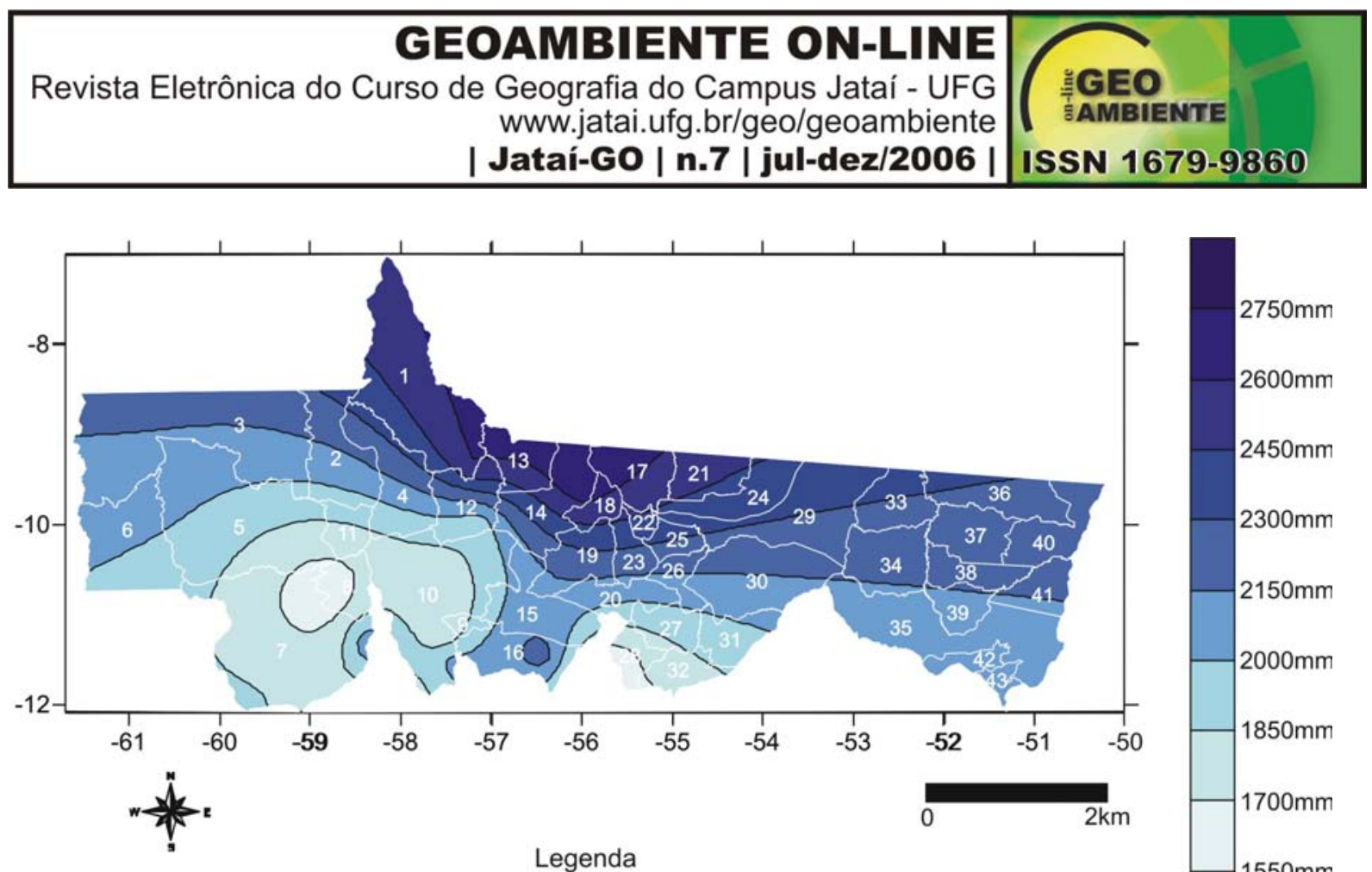

1-Apiacás, 2-Cotriguaçu, 3-Colniza, 4-Nova Bandeirante, 5-Aripuanã, 6-Rondolândia, 7Juína, 8-Castanheira, 9-Novo Horizonte do Norte, 10-Juara, 11-Juruena, 12-Nova Monte Verde, 13Paranaíta, 14-Alta Floresta, 15-Tabaporã, 16-Porto dos Gaúchos, 17-Novo Mundo, 18-Carlinda,19Nova Canaã do Norte, 20-Itaúba, 21-Guarantã do Norte, 22-Nova Guarita, 23-Colíder, 24-Matupá, 25-Terra Nova do Norte, 26-Nova Santa Helena, 27-Claúdia, 28-Sinop, 29-Peixoto de Azevedo, 30Marcelândia, 31-União do Sul, 32-Santa Carmem, 33-Santa Cruz do Xingu, 34-São José do Xingu, 35-São Félix do Araguaia, 36-Vila Rica, 37-Confresa, 38-Porto Alegre do Norte, 39-Canabrava do Norte, 40-Santa Terezinha, 41-Luciara, 42-Alto Boa Vista e 43-Serra Nova Dourada.

Figura 2: Mapa pluviométrico de 1990.

De acordo com a (Figura 2), as maiores intensidades chuvosas de 2.450 até $2.750 \mathrm{~mm}$ ocorreram nas porções Norte, nos municípios de Alta Floreta, Apiacas, Paranaíta, Carlinda, Novo Mundo e Guarantã do Norte, sendo que a Oeste, Sul e a Leste foi nos municípios de Castanheira, Juara, Cotriguaçu, Novo Horizonte do Norte, Nova Bandeirantes, Juína, Alto Boa Vista Canabrava do Norte, Castanheira, Claúdia, Colíder, Colniza, Confresa, Cotriguaçu, Itaúba, Juara, Juína, Juruena, Luciara, Matupá, Marcelândia, Nova Bandeirante, Nova Canaã do Norte, Nova Guarita, Nova Monte Verde, Nova Santa Helena, Novo Horizonte do Norte, Peixoto de Azevedo, Porto Alegre do Norte, Porto dos Gaúchos, Rondolândia, Santa Carmem, Santa Cruz do Xingu, Santa Terezinha, São Félix do Araguaia, São José do Xingu, Serra Nova Dourada, Sinop, Tabaporã, Terra Nova do Norte, União do Sul e Vila Rica com registros de 1.550 até $2.300 \mathrm{~mm}$.

A soma da chuva com registro de $2.500 \mathrm{~mm}$ ocorridos no ano de 1991(Figura 3), estiveram presentes nos sentidos Norte da área de estudo nos municípios de Nova Monte Verde, Nova Canaã do Norte e Alta Floresta, assim da mesma porção em direção a Leste, a pluviometria foi registrada com $2.350 \mathrm{~mm}$, abrangendo os municípios de Alto Boa Vista, Apiacás, Canabrava do Norte, Carlinda, Castanheira, Claúdia, Colíder, Colniza, Confresa, 
Guarantã do Norte, Itaúba, Luciara, Matupá, Marcelândia, Nova Bandeirante, Nova Canaã do Norte, Nova Guarita, Nova Monte Verde, Nova Santa Helena, Novo Horizonte do Norte, Novo Mundo, Paranaíta, Peixoto de Azevedo, Porto Alegre do Norte, Porto dos Gaúchos, Rondolândia, Santa Carmem, Santa Cruz do Xingu, Santa Terezinha, São Félix do Araguaia, São José do Xingu, Serra Nova Dourada, Sinop, Tabaporã, Terra Nova do Norte, União do Sul e Vila Rica.

Enquanto isso a da área de estudo Oeste e Sul nos municípios de Colniza, Aripuanã, Carlinda, Castanheira, Itaúba, Juína, Juara, Juruena, Rondolândia, Sinop, Porto dos Gaúchos Tabaporã, a variabilidade pluviométrica com os menores índices pluviométricos foram registrados de 1.600 até $2.050 \mathrm{~mm}$.

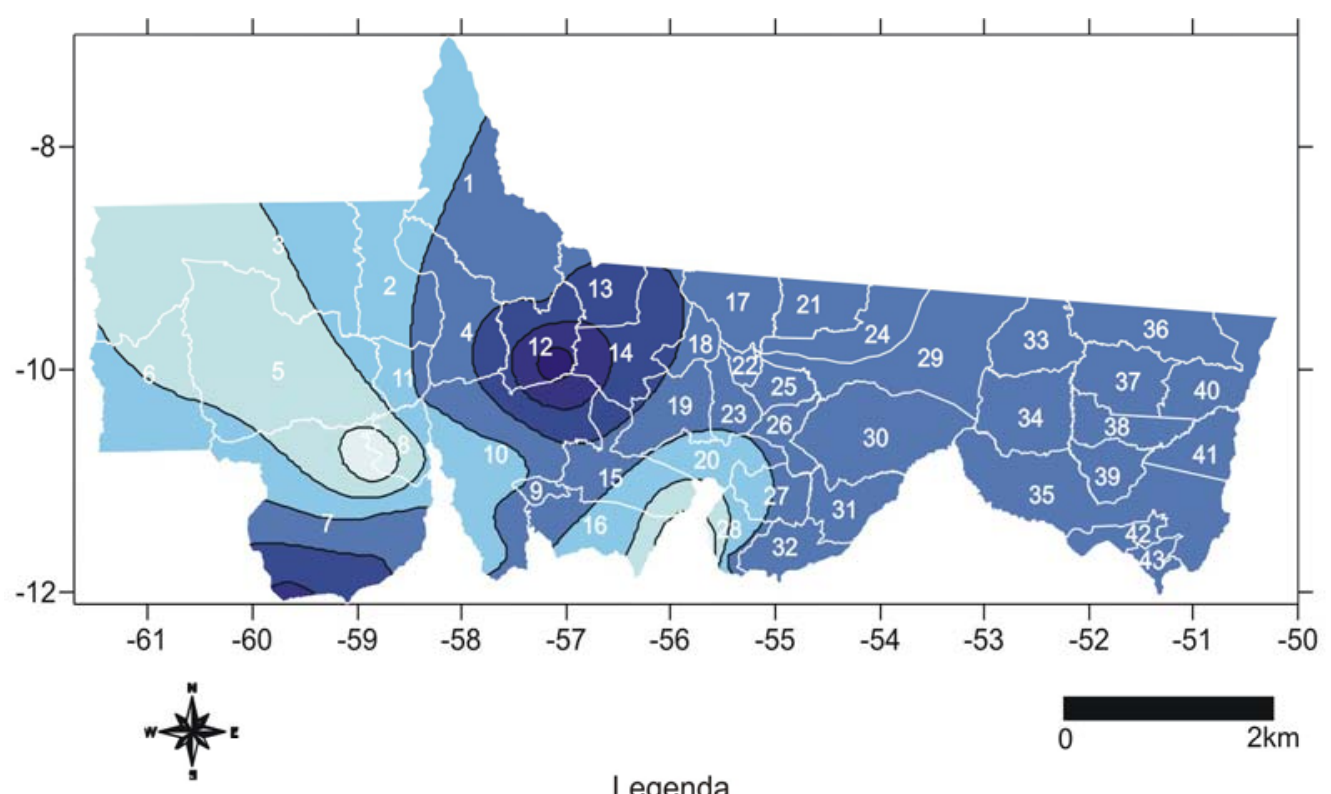

1-Apiacás, 2-Cotriguaçu, 3-Colniza, 4-Nova Bandeirante, 5-Aripuanã, 6Rondolândia, 7-Juína, 8-Castanheira, 9-Novo Horizonte do Norte, 10-Juara, 11Juruena, 12-Nova Monte Verde, 13-Paranaíta, 14-Alta Floresta, 15-Tabaporã, 16Porto dos Gaúchos, 17-Novo Mundo, 18-Carlinda,19-Nova Canaã do Norte, 20Itaúba, 21-Guarantã do Norte, 22-Nova Guarita, 23-Colíder, 24-Matupá, 25Terra Nova do Norte, 26-Nova Santa Helena, 27-Claúdia, 28-Sinop, 29-Peixoto de Azevedo, 30-Marcelândia, 31-União do Sul, 32-Santa Carmem, 33-Santa Cruz do Xingu, 34-São José do Xingu, 35-São Félix do Araguaia, 36-Vila Rica, 37Confresa, 38-Porto Alegre do Norte, 39-Canabrava do Norte, 40-Santa Terezinha, 41-Luciara, 42-Alto Boa Vista e 43-Serra Nova Dourada.

Figura 3: Mapa pluviométrico de 1991. 


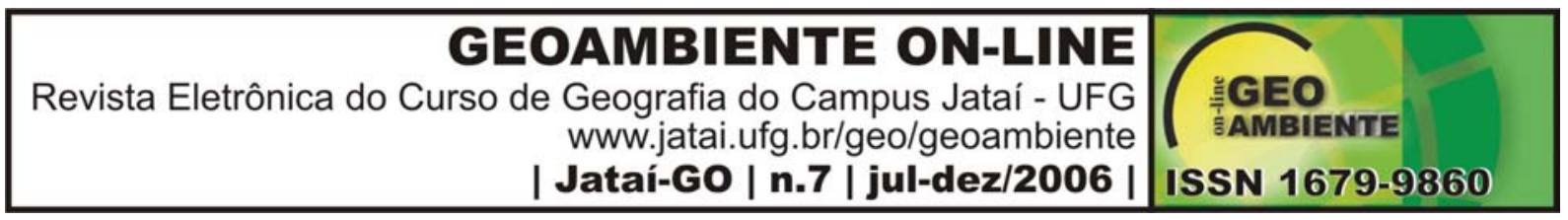

As intensidades pluviométricas, registradas no ano de 1992, (Figura 4), teve um acúmulo bem significativo anotado de 2.050 até $2.500 \mathrm{~mm}$, entre as porções Norte e Leste da área de estudo, respectivamente nos municípios de Alta Floresta, Alto Boa Vista, Canabrava do Norte, Carlinda, Claúdia, Colíder, Confresa, Guarantã do Norte, Itaúba, Luciara, Matupá, Marcelândia, Nova Bandeirante, Nova Canaã do Norte, Nova Guarita, Nova Monte Verde, Nova Santa Helena, Novo Horizonte do Norte, Novo Mundo, Paranaíta, Peixoto de Azevedo, Porto Alegre do Norte, Santa Carmem, Santa Cruz do Xingu, Santa Terezinha, São Félix do Araguaia, São José do Xingu, Serra Nova Dourada, Tabaporã, Terra Nova do Norte, União do Sul e Vila Rica.

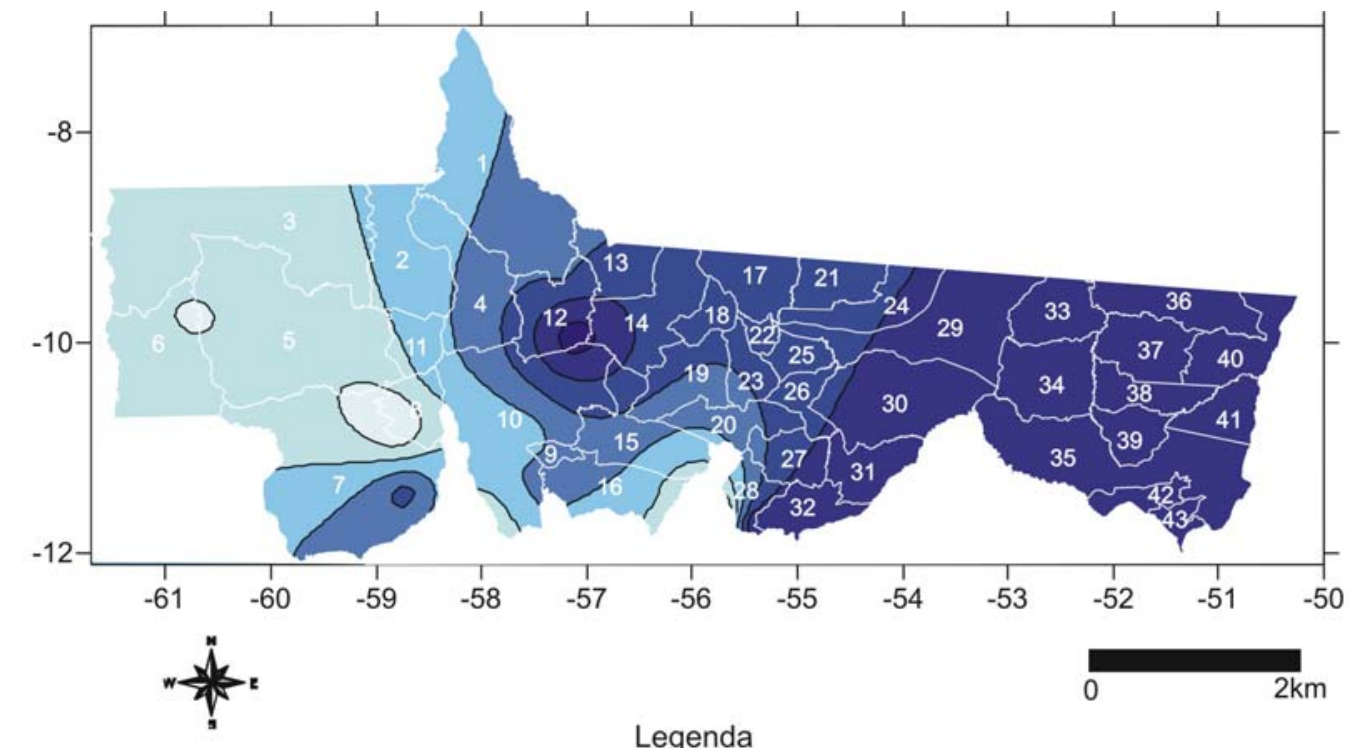

1-Apiacás, 2-Cotriguaçu, 3-Colniza, 4-Nova Bandeirante, 5-Aripuanã, 6-Rondolândia, 7Juína, 8-Castanheira, 9-Novo Horizonte do Norte, 10-Juara, 11-Juruena, 12-Nova Monte Verde, 13Paranaíta, 14-Alta Floresta, 15-Tabaporã, 16-Porto dos Gaúchos, 17-Novo Mundo, 18-Carlinda,19Nova Canaã do Norte, 20-Itaúba, 21-Guarantã do Norte, 22-Nova Guarita, 23-Colíder, 24-Matupá, 25-Terra Nova do Norte, 26-Nova Santa Helena, 27-Claúdia, 28-Sinop, 29-Peixoto de Azevedo, 30Marcelândia, 31-União do Sul, 32-Santa Carmem, 33-Santa Cruz do Xingu, 34-São José do Xingu, 35-São Félix do Araguaia, 36-Vila Rica, 37-Confresa, 38-Porto Alegre do Norte, 39-Canabrava do Norte, 40-Santa Terezinha, 41-Luciara, 42-Alto Boa Vista e 43-Serra Nova Dourada.

Figura 4: Mapa pluviométrico do ano 1992.

Ainda observando a (Figura 4), entre 1.450 até $1.900 \mathrm{~mm}$, os menores índices pluviométricos acumulados ocorreram nos municípios de Apiacás, Aripuanã, Rondolândia, Juruena, Juína, Juara, Porto dos Gaúchos, Cotriguaçu, Castanheira, Colniza e Sinop.

Os maiores índices pluviométricos foram registrados no ano de 1993 (Figura 5), nas porções Norte, Leste e parte do Oeste de 1.900 até $2.350 \mathrm{~mm}$, abrangendo os municípios de Alto Boa Vista, Apiacás, Canabrava do Norte, Carlinda, Colíder, Colniza, Confresa, Cotriguaçu, Guarantã do Norte, Juruena, Luciara, Matupá, Marcelândia, Nova Bandeirante, 
Nova Guarita, Nova Santa Helena, Novo Mundo, Paranaíta, Peixoto de Azevedo, Porto Alegre do Norte, Santa Cruz do Xingu, Santa Terezinha, São Félix do Araguaia, São José do Xingu, Serra Nova Dourada, Terra Nova do Norte, União do Sul e Vila Rica.

Enquanto isso nas porções Sul e na outra metade da porção Oeste, foram anotadas as menores somas pluviométricas de 1.450 até $1.750 \mathrm{~mm}$, sendo que esta pluviometria foi apresentada nos municípios de Alta Floresta, Aripuanã, Castanheira, Claúdia, Itaúba, Juara, Juína, Nova Canaã do Norte, Nova Monte Verde, Novo Horizonte do Norte, Porto dos Gaúchos, Rondolândia, Santa Carmem, Tabaporã e Sinop.
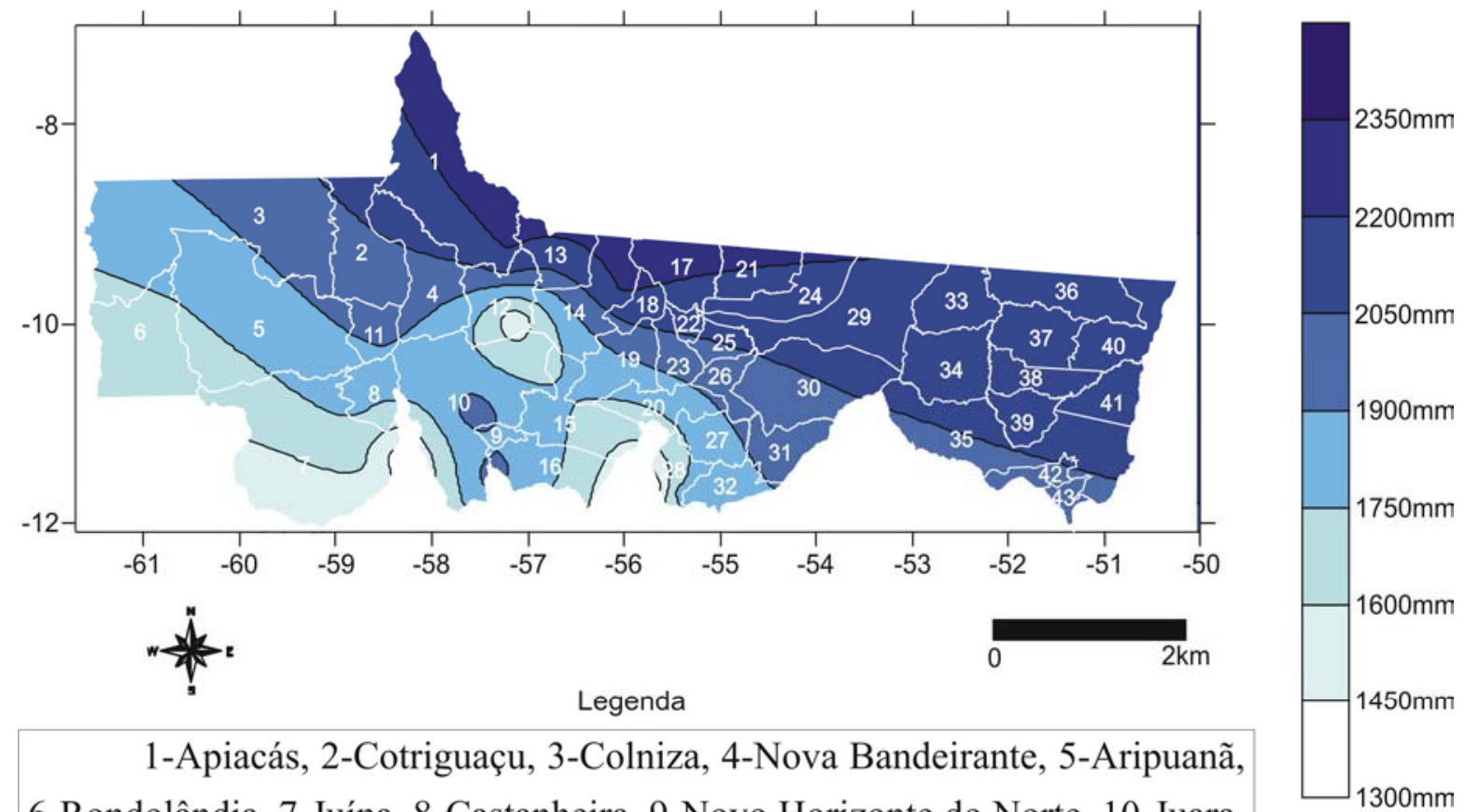

6-Rondolândia, 7-Juína, 8-Castanheira, 9-Novo Horizonte do Norte, 10-Juara, 11-Juruena, 12-Nova Monte Verde, 13-Paranaíta, 14-Alta Floresta, 15Tabaporã, 16-Porto dos Gaúchos, 17-Novo Mundo, 18-Carlinda,19-Nova Canaã do Norte, 20-Itaúba, 21-Guarantã do Norte, 22-Nova Guarita, 23Colíder, 24-Matupá, 25-Terra Nova do Norte, 26-Nova Santa Helena, 27Claúdia, 28-Sinop, 29-Peixoto de Azevedo, 30-Marcelândia, 31-União do Sul, 32-Santa Carmem, 33-Santa Cruz do Xingu, 34-São José do Xingu, 35-São Félix do Araguaia, 36-Vila Rica, 37-Confresa, 38-Porto Alegre do Norte, 39Canabrava do Norte, 40-Santa Terezinha, 41-Luciara, 42-Alto Boa Vista e 43Serra Nova Dourada.

Figura 5: Mapa pluviométrico do ano 1993.

O ano de 1994 a maior pluviometria observada foi de $2.450 \mathrm{~mm}$, no município de Juruena (Figura 6) que inserido na porção Oeste, e nos demais municípios vizinhos em direção à porção Leste à soma pluviométrica foi registrada de 2.150 até $2.300 \mathrm{~mm}$, nos 
municípios de Aripuanã, Castanheira, Colniza, Cotriguaçu, Juruena, Nova Monte Verde e Rondolândia.

Nas porções Sul, Norte e Leste mais respectivamente nos municípios de Alta Floresta, Alto Boa Vista, Apiacás, Canabrava do Norte, Carlinda, Claúdia, Colíder, Confresa, Guarantã do Norte, Itaúba, Juara, Juína, Luciara, Matupá, Marcelândia, Nova Canaã do Norte, Nova Guarita, Nova Santa Helena, Novo Horizonte do Norte, Novo Mundo, Paranaíta, Peixoto de Azevedo, Porto Alegre do Norte, Porto dos Gaúchos, Santa Carmem, Santa Cruz do Xingu, Santa Terezinha, São Félix do Araguaia, São José do Xingu, Serra Nova Dourada, Sinop, Tabaporã, Terra Nova do Norte, União do Sul e Vila Rica os registros pluviométricos foram bem variáveis com a soma de 1.750 até $2.150 \mathrm{~mm}$.

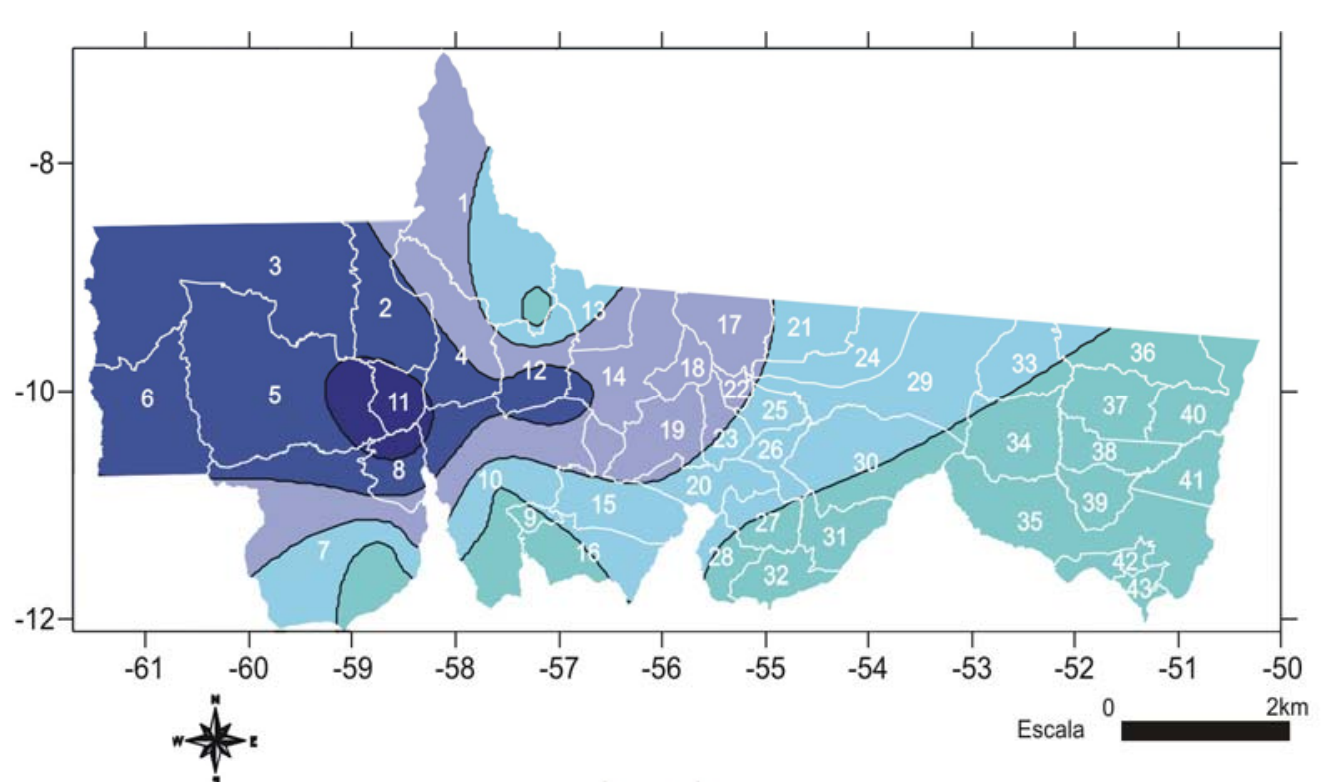

Legenda

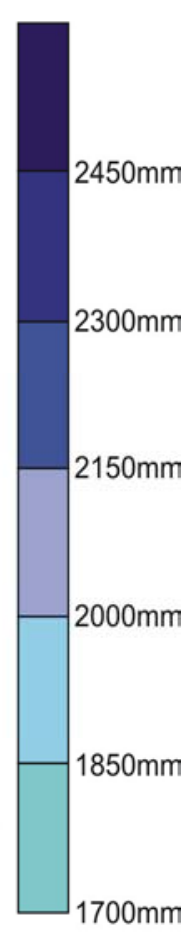

6-Rondolândia, 7-Juína, 8-Castanheira, 9-Novo Horizonte do Norte, 10-Juara, 11-Juruena, 12-Nova Monte Verde, 13-Paranaíta, 14-Alta Floresta, 15Tabaporã, 16-Porto dos Gaúchos, 17-Novo Mundo, 18-Carlinda,19-Nova Canaã do Norte, 20-Itaúba, 21-Guarantã do Norte, 22-Nova Guarita, 23-Colíder, 24Matupá, 25-Terra Nova do Norte, 26-Nova Santa Helena, 27-Claúdia, 28-Sinop, 29-Peixoto de Azevedo, 30-Marcelândia, 31-União do Sul, 32-Santa Carmem, 33-Santa Cruz do Xingu, 34-São José do Xingu, 35-São Félix do Araguaia, 36Vila Rica, 37-Confresa, 38-Porto Alegre do Norte, 39-Canabrava do Norte, 40Santa Terezinha, 41-Luciara, 42-Alto Boa Vista e 43-Serra Nova Dourada.

Figura 6: Mapa pluviométrico do ano 1994. 
O maior volume pluviométrico observado na (Figura 7) referente ao ano de 1995 ocorreu na porção Oeste, no município de Juara, com destaque de $2.700 \mathrm{~mm}$, e nos municípios Aripuanã, Castanheira, Colniza, Cotriguaçu, Juína, Juruena, Rondolândia, os registros foram de 2.250 até $2.550 \mathrm{~mm}$.
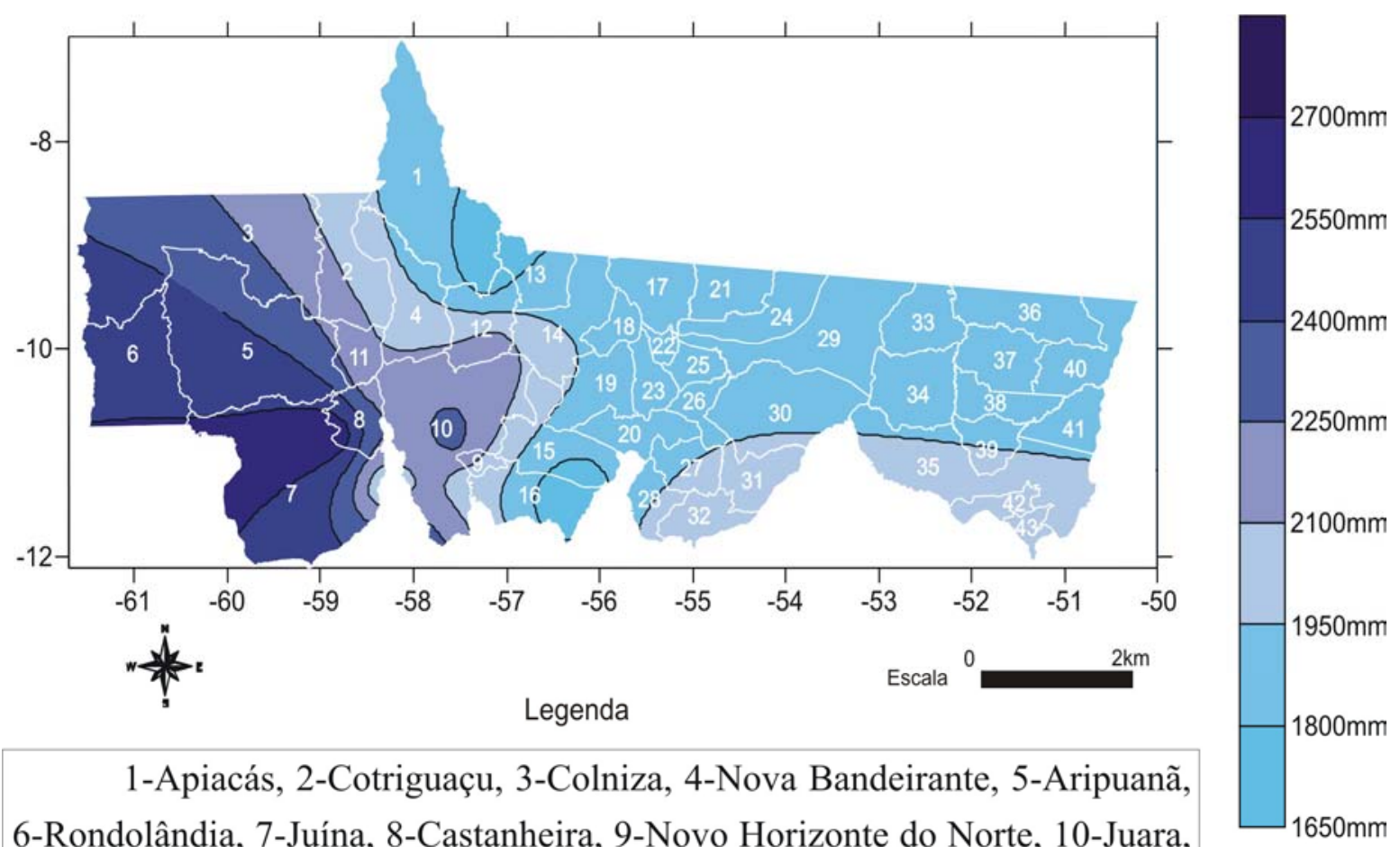

6-Rondolândia, 7-Juína, 8-Castanheira, 9-Novo Horizonte do Norte, 10-Juara, 11-Juruena, 12-Nova Monte Verde, 13-Paranaíta, 14-Alta Floresta, 15Tabaporã, 16-Porto dos Gaúchos, 17-Novo Mundo, 18-Carlinda,19-Nova Canaã do Norte, 20-Itaúba, 21-Guarantã do Norte, 22-Nova Guarita, 23-Colíder, 24Matupá, 25-Terra Nova do Norte, 26-Nova Santa Helena, 27-Claúdia, 28-Sinop, 29-Peixoto de Azevedo, 30-Marcelândia, 31-União do Sul, 32-Santa Carmem, 33-Santa Cruz do Xingu, 34-São José do Xingu, 35-São Félix do Araguaia, 36Vila Rica, 37-Confresa, 38-Porto Alegre do Norte, 39-Canabrava do Norte, 40Santa Terezinha, 41-Luciara, 42-Alto Boa Vista e 43-Serra Nova Dourada.

Figura 7: Mapa pluviométrico do ano 1995.

Ainda de acordo com a mesma (Figura 7), percebeu-se que os menores volumes pluviométricos de 1.650 , até $2.250 \mathrm{~mm}$, foram registrados nas porções Norte, Sul e Leste da área de estudo, ou seja, nos municípios de Alta Floresta, Alto Boa Vista, Apiacás, Canabrava do Norte, Carlinda, Claúdia, Colíder, Confresa, Guarantã do Norte, Itaúba, Luciara, Matupá, Marcelândia, Nova Bandeirante, Nova Canaã do Norte, Nova Guarita, Nova Monte Verde, Nova Santa Helena, Novo Horizonte do Norte, Novo Mundo, Paranaíta, Peixoto de Azevedo, Porto Alegre do Norte, Porto dos Gaúchos, Santa Carmem, Santa Cruz do Xingu, Santa 


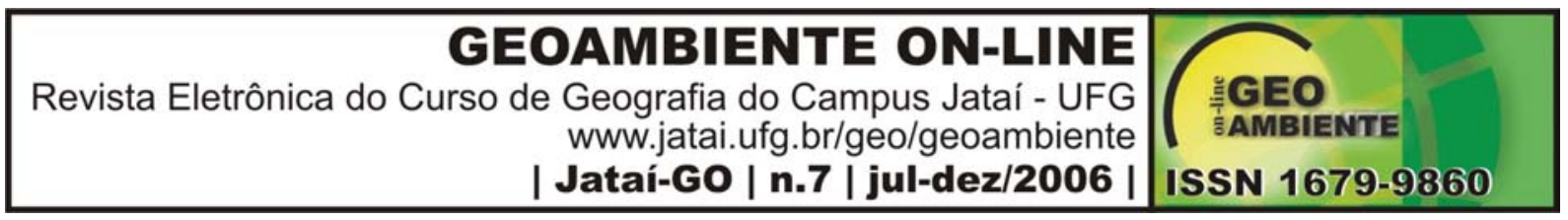

Terezinha, São Félix do Araguaia, São José do Xingu, Serra Nova Dourada, Sinop, Tabaporã, Terra Nova do Norte, União do Sul e Vila Rica.

No ano de 1996 (Figura 8), os maiores volumes pluviométricos foram perceptíveis nos municípios de Aripuanã, Carlinda, Castanheira, Colniza, Cotriguaçu, Juara, Juína, Juruena, Nova Monte Verde, Novo Horizonte do Norte, e Rondolândia, sendo que estes municípios estão inseridos na porção Oeste e Norte da área de estudo com registros de 1.950 até $2.400 \mathrm{~mm}$. Já nas porções Leste e Sul, as somatórias pluviométricas foram de 1.500 até 1.950mm, representados nos municípios de Alta Floresta, Alto Boa Vista, Apiacás, Canabrava do Norte, Claúdia, Colíder, Confresa, Guarantã do Norte, Itaúba, Luciara, Matupá, Marcelândia, Nova Bandeirante, Nova Canaã do Norte, Nova Guarita, Nova Santa Helena, Novo Mundo, Paranaíta, Peixoto de Azevedo, Porto Alegre do Norte, Porto dos Gaúchos, Santa Carmem, Santa Cruz do Xingu, Santa Terezinha, São Félix do Araguaia, São José do Xingu, Serra Nova Dourada, Sinop, Tabaporã, Terra Nova do Norte, União do Sul e Vila Rica.

Segundo Assad \& Sano (1993), o clima do Planalto Central é caracterizado por uma estação seca bem característica e outra bem chuvosa. Este fator pode ser de uma maneira geral, generalizado para toda a Região do Centro-Oeste do Brasil, apresentando assim uma certa irregularidade pluviométrica, o que acarreta à variabilidade pluviométrica, espacial e/ou temporal, onde tal acontecimento pode ocasionar efeitos danosos a solos desprotegidos de cobertura vegetal.

As quantidades de precipitações médias de longo prazo, para o mês e estação do ano dificilmente indicam regularidades, ou a confiabilidade regular das chuvas, quando as precipitações se mostram bem variáveis, todavia deve-se estudar o regime pluviométrico, com o intuito de se identificar à variabilidade pluviométrica, para que se realize um melhor planejamento, uma vez que em nenhuma parte do mundo as precipitações são regulares (Ayoade, 2004). 

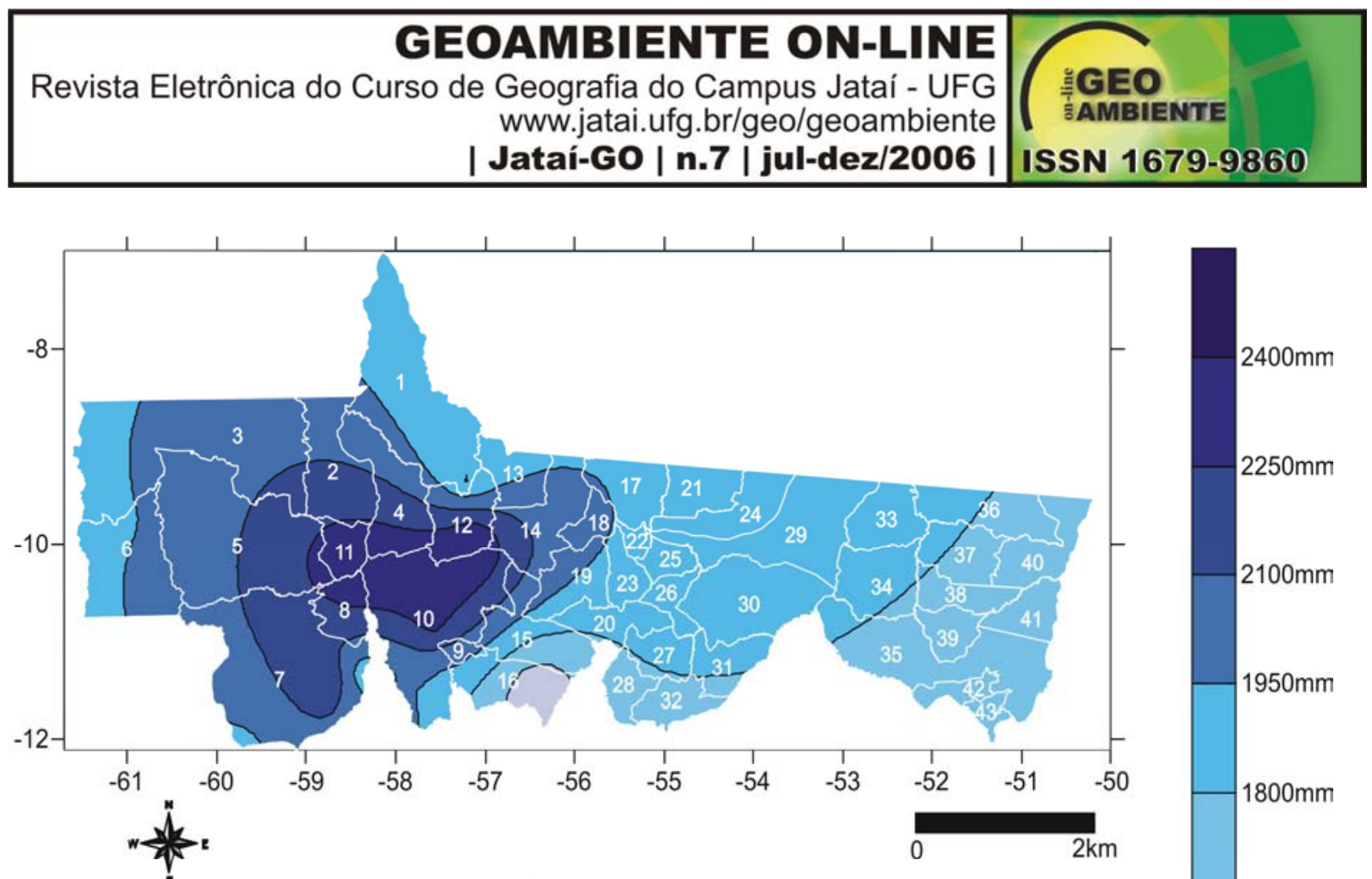

Legenda

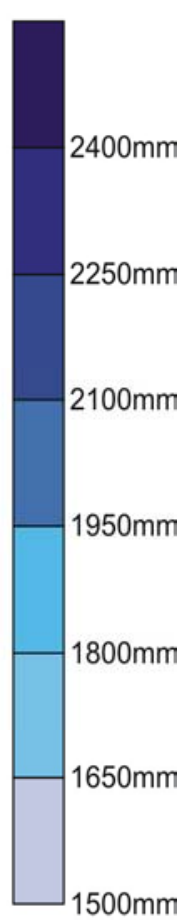

6-Rondolândia, 7-Juína, 8-Castanheira, 9-Novo Horizonte do Norte, 10-Juara, 11-Juruena, 12-Nova Monte Verde, 13-Paranaíta, 14-Alta Floresta, 15-Tabaporã, 16-Porto dos Gaúchos, 17-Novo Mundo, 18-Carlinda,19-Nova Canaã do Norte, 20-Itaúba, 21-Guarantã do Norte, 22-Nova Guarita，23-Colíder，24-Matupá, 25-Terra Nova do Norte, 26-Nova Santa Helena, 27-Claúdia, 28-Sinop, 29Peixoto de Azevedo, 30-Marcelândia, 31-União do Sul, 32-Santa Carmem, 33Santa Cruz do Xingu, 34-São José do Xingu, 35-São Félix do Araguaia, 36-Vila Rica, 37-Confresa, 38-Porto Alegre do Norte, 39-Canabrava do Norte, 40-Santa Terezinha, 41-Luciara, 42-Alto Boa Vista e 43-Serra Nova Dourada.

Figura 8: Mapa pluviométrico do ano 1996.

\section{4 - Conclusões}

- Os municípios em que houve os maiores acúmulos pluviométricos, com volumes que chegaram até $2.750 \mathrm{~mm}$, ao longo dos 6 (seis) anos de estudos foram: Alta Floresta, Cotriguaçu, Paranaíta, Juara, Juruena, Nova Monte Verde, Nova Bandeirante, Colniza, Rondolândia, Aripuanã, e Castanheira, sendo estes situados, nas porções Norte e Oeste da área de estudo. Enquanto isso no Sul da área, estudo, os municípios que menos registraram índices pluviométricos foram: Sinop, Santa Carmem, Porto dos Gaúchos, Juína, Juara, Novo Horizonte do Norte e Itaúba. Então o sentido Leste da área, ao longo da série estudada, sempre apresentou variação pluviométrica oscilante.

- A partir da análise dos mapas de isoietas de 1990 a 1996, identificou-se que, preferencialmente, as chuvas ocorreram em maior quantidade nas porções Norte e 
Oeste da área de estudos. Contudo nas porções Sul e Leste, foram registrados os menores índices pluviométricos, com exceção apenas para os anos de 1992 e 1993, onde foram registradas as maiores pluviometrias.

- Na área estudada no extremo Norte do Estado de Mato Grosso, ocorreu uma variabilidade pluviométrica, ao longo da série estudada, onde a chuva foi bem irregular, durante todos os anos analisados.

- Outro fator interessante averiguado foi que, quase todos os índices pluviométricos ficaram sempre abaixo dos volumes estipulados em anos anteriores, com exceção apenas para os anos de 1990 e 1991, que atingiram os volumes anuais máximos.

- Portanto, a chuva foi distribuída de forma bem irregular durante este período de estudos, onde em alguns municípios as precipitações pluviométricas foram acentuadas, e em outros, menos expressivas.

- Dessa forma, diante de toda a dinâmica de variabilidade das chuvas atuantes regionalmente, é necessário há realização de outros estudos pluviométricos mais detalhados, com outras fontes de dados, e possivelmente uma ampliação da rede de monitoramento, uma vez que os constantes desmatamentos, os cultivos de grãos, mineração e a pecuária têm se destacado localmente como economia, assim a população tem utilizado o meio físico de uma maneira, muitas vezes imprópria. Espera-se que os resultados contidos neste artigo sirvam para orientar os planejadores rurais e urbanos na recomendação de obras de proteção de encostas, reservatórios, queimadas, reservas legais, indicações de práticas e manejos de solos para a região do Cerrado.

\section{5 - Referências bibliográficas}

AYOADE, J. O. Introdução à climatologia para os trópicos. Ed. Bertrand Brasil, 10a edição, Rio de Janeiro, RJ.332p. 2004.

ASSAD, E. D.; SANO, E. E.; MASUTOMO, R.; CASTRO, L. H. \& SILVA, F. A. M.. Veranicos na região dos cerrados brasileiros freqüência e probabilidade de ocorrência. In: Chuva nos Cerrados. ASSAD, E. D. (Coordenador). BRASIL/ EMBRAPA Empresa Brasileira de Pesquisas Agropecuárias, Brasília, DF. 423 p. 1994.

ASSAD, M. L. L.; ASSAD, E. D.; \& EVANGELISTA, B. A. Chuvas extremas na região dos cerrados. In: Chuva nos Cerrados. ASSAD, E. D. (Coordenador), BRASIL/ EMBRAPA, Empresa Brasileira de Pesquisas Agropecuárias, Brasília, DF. 423 p, 1994. 


\section{GEOAMBIENTE ON-LINE}

Revista Eletrônica do Curso de Geografia do Campus Jataí - UFG www.jatai.ufg.br/geo/geoambiente

| Jataí-GO | n.7 | jul-dez/2006 |

ASSAD, E. D. \& SANO, E. E. Sistema de informações geográficas: aplicações na agricultura. BRASIL/EMBRAPA, Empresa Brasileira de Pesquisas Agropecuárias, Planaltina, DF. 274 p, 1993.

BITTENCOURT ROSA, D.; ALVES da SILVA, M.; \& MENEZES LIMA, P. R. 1997. As Características Geológicas e Mineralógicas do Granitóide Paranaíta. In: SIMPÓSIO DE GEOLOGIA DO CENTRO OESTE, 6, Cuiabá, MT, UFMT, Sociedade Brasileira de Geologia, Núcleo Centro Oeste, Cuiabá, MT.Anais do. p.3 - 7, 1997.

BITTENCOURT ROSA, D.; GELA, A.; ALVES, D. de. O.; MACEDO, M.; GARCIA NETTO, L. da. R.; PINTO, S. D. S.; BORGES, C. A.; ROSSETO, O. C.; TOCANTINS, N.; LOPES dos SANTOS, P \& GERALDO, A. C. H. Um Estudo Geoambiental Comparativo das Características Morfoestruturais e Morfoesculturais nas Áreas das Bacias do Alto Rio Paraguai e do Rio Teles Pires no Estado de Mato Grosso. Projeto de Pesquisa, Rel. Final FAPEMAT/CNPq, Cuiabá, MT. 319 p, 2002.

CASARIM, D.P. Um estudo observacional sobre os sistemas de bloqueio no hemisfério Sul. In: Chuva nos Cerrados. ASSAD, E. D. (Coordenador), Empresa Brasileiro de pesquisas agropecuárias de Pesquisas Agropecuárias dos Cerrados-EMBRAPA/CPAC, Brasília, DF. 423p. 1983.

DERBY, O. A. Nota sobre a Geologia e a Paleontologia de Mato Grosso. Archivos do Museu Nacional, (9): Rio de Janeiro. 59 - 88, 1895.

DURAND-DASTÈS, F. Climatologie, Encyclopaedia Universalis, 4, p. 618 - 624 . 1968.

EMBRAPA/BRASIL. Empresa Brasileira de Pesquisa Agropecuária. Sistema Brasileiro de Classificação dos Solos. Brasília, DF. 429 p.1999.

ESTIENNE, P. \& GODARD, A. Climatologie. Armand Colin, Collection U, Paris. 365 p.1970.

SILVA, G. H.; LEAL, J. W. L.; MONTALVÃO, R. M. G. de.; BEZERRA, P. E. L.; PIMENTA, O. N. dos.; TASSINARI, C. C. G. \& FERNANDES, C.A.C. Geologia, Folha SC/21 - Juruena. BRASIL. Ministério das Minas e Energia, Departamento Nacional da Produção Mineral, Projeto RADAMBRASIL, (Levantamento dos Recursos Naturais, 20), Rio de Janeiro, RJ. p. 21 - 117, 1980.

MATHERON, G. Les variables régionalises et leur estimation. Masson, Paris, 305p. 1965.

MELO, D. P. \& FRANCO, M. do. S. M. Geomorfologia. Folha SC/21. BRASIL. Departamento Nacional da Produção Mineral. Projeto RADAMBRASIL (Levantamento dos Recursos Naturais, 20), Rio de Janeiro, RJ. 117 - 164 p, 1980. 
MONTEIRO, C. A. F. de. A dinâmica climática e as chuvas no Estado de São Paulo. Universidade Estadual Paulista Júlio de Mesquita Filho-UNESP, Rio Claro, SP, Cd-rom. 2000.

MONTEIRO, C. A. F. de.; MARKUS, E. \& GOMES, K. M. F. Comparação da Pluviosidade nos Estados de São Paulo e Rio Grande do Sul nos Invernos de 1957 e 1963. In: Laboratório de Climatologia, Instituto de Geografia, USP, São Paulo, SP. 1971.

NIMER, E. Climatologia do Brasil, BRASIL. IBGE, 422 p, Rio de Janeiro, RJ. 1979.

NIMER, E. \& BRANDÃO, A. M. P. M. Balanço hídrico e clima da região dos cerrados. BRASIL. IBGE, 166 p, Rio de Janeiro, RJ. 1989.

RAMADE, F. Eléments d'Ecologie Appliquée, Paris, McGraw-Hill. 1974.

ROSSATO, P. S.; SARTORI M. G. B.; MISSIO, L. R. \& ROSA, J. L. A gênese das enchentes de São Miguel na região central do Rio Grande do Sul. In: CONGRESSO BRASILEIRO DE AGROMETEOROLOGIA, XIII, Santa Maria, RS, Cd-rom. 2003.

SANT'ANNA NETO, J. L. As chuvas no Estado de São Paulo: A variabilidade pluvial nos últimos 100 anos. In: Variabilidade e mudanças climáticas, implicações ambientais e socioeconômicas. SANT'ANNA NETO, J. L. \& ZAVATINI, J. A., (Orgs.) Maringá, PR: Eduem, p.95-112. 2000.

SERRA, A. Previsão do Tempo. In: Boletim Geográfico, IBGE, Rio de Janeiro, RJ. 1948.

SERRA, A. \& RATISBONNA, L. As massas de ar na América do Sul, Serviço de Meteorologia do Ministério da Agricultura, Rio de Janeiro, RJ. 59 p, 1942.

SETTE. D. M. Os sistemas atmosféricos de superfície, a circulação secundária e os principais tipos de tempo que atuam no centro do continente sul americano - Mato Grosso - Brasil. In: SIMPÓSIO BRASILEIRO DE CLIMATOLOGIA GEOGRÁFICA, V, Curitiba, PR, Cd-rom. 2002.

TARIFA, J. R.; SETTE, D. M.; MADRUGA, L. C. MOREIRA, M. L. C.; ORMOND, G. L.; FILHO, V. D.; SANTOS, J. F. Atlas climatológico de Mato Grosso: Departamento de Geografia-Universidade Federal de Mato Grosso (UFMT), Cd-rom, Rondonópolis, MT. 2006. VILA, R. C. Os segredos do tempo. Fundação Getúlio Vargas, Rio de Janeiro, RJ. 143 p, 1975.

WERLE, H. J. S. \& ALVES da SILVA, M. Unidades do Relevo de Mato Grosso: Uma Proposta de Classificação. Revista Sociedade \& Natureza, Departamento de Geografia, Universidade Federal de Uberlândia (UFU), Uberlândia, MG.Ano 3, n. 15, p. 409 - 415, 1996. 